\title{
BUSINESS AND NATURAL ENVIRONMENT RESEARCH IN THE ANTHROPOCENE: IS THE CIRCULAR ECONOMY THE WAY FORWARD?
}

\section{De Angelis, Roberta}

\section{Cardiff University Business School}

As humanity has entered the Anthropocene - a new geological epoch marked by an unprecedented human impact upon planet Earth - questions arise about the relevance of extant management research in guiding environmentally sustainable corporate outcomes. Management studies have rarely looked beyond the boundaries of the social sciences disciplines to theorise about sustainable development. Yet for the latter to be achieved, more transdisciplinary efforts are required. This article draws on circular economy principles to suggest some constructs to build a theory of sustainability management research in the Anthropocene. By enlightening the correlation existing between circular economy principles and functional principles in nature, it also contributes to advance the conceptual foundations of the circular economy, which remain poorly investigated. 